\title{
Ixabepilone development across the breast cancer continuum: a paradigm shift
}

\author{
This article was published in the following Dove Press journal: \\ Cancer Management and Research \\ 24 June 2010 \\ Number of times this article has been viewed
}

\author{
Nuhad K Ibrahim \\ Department of Breast Medical \\ Oncology, The University of Texas \\ MD Anderson Cancer Center, \\ Houston, TX, USA
}

\begin{abstract}
The epothilone analog ixabepilone exhibits reduced susceptibility to several important tumor survival mechanisms that limit the efficacy of taxanes and anthracyclines. As a single agent, ixabepilone has shown promise in metastatic breast cancer when anthracyclines, taxanes, or capecitabine have failed; and in early-stage breast cancer that is taxane-naïve or has previously received taxanes in the adjuvant or metastatic setting. Compared with capecitabine alone, ixabepilone used in combination with capecitabine in patients previously treated with and resistant to anthracyclines and taxanes produced a $25 \%$ reduction in the risk of disease progression. Triple-negative tumors showed particular susceptibility to this doublet. Ixabepilone has also demonstrated efficacy as first-line therapy in combination with targeted agents such as bevacizumab and trastuzumab. Ongoing investigations should provide insight as to how this agent could be integrated into treatment of early-stage disease. In clinical studies, toxicities with ixabepilone were manageable and reversible through dose reduction or delay, even in patients with extensive or heavily-pretreated disease. Thus, ixabepilone represents a useful addition to the therapeutic options available for advanced breast cancer, and it may extend progression-free survival in patients with limited treatment options.
\end{abstract}

Keywords: ixabepilone, breast cancer, efficacy, metastasis, adjuvant

\section{Introduction}

Current treatment strategies for breast cancer depend on disease stage, tumor grade, tumor hormone receptor status, and whether there is over-expression or amplification of the human epidermal growth factor receptor (HER). Because of the availability of numerous agents, patients with breast cancer may receive several different lines of treatment throughout the course of their disease. Once the disease has reached the metastatic stage, therapeutic strategies are chosen because they have the potential to achieve symptom palliation while significantly prolonging progression-free survival (PFS). ${ }^{1-7}$

However, tumors may respond to many available agents by upregulating survival pathways. ${ }^{8}$ These mechanisms can render the tumor resistant to multiple, sometimes unrelated classes of therapy, presenting an enormous clinical challenge. If tumor resistance develops, the disease may eventually progress despite therapy, necessitating use of agents that are believed to have no cross resistance to previously used drugs, or agents that are able to circumvent such resistance. ${ }^{9,10}$ Furthermore, some patients have innate resistance to a particular drug or regimen and may not respond at all. ${ }^{9}$ Because tumors may adapt to anticancer agents, response rates and survival outcomes tend to decrease with each subsequent line of therapy. Given that most patients with recurrent breast cancer have already been exposed to an anthracycline 
(eg, doxorubicin, epirubicin) and a taxane (eg, paclitaxel, docetaxel) in the adjuvant setting, there is a need for therapies that are noncross-resistant with these two classes of cytotoxic agents.

The epothilones comprise a novel class of chemotherapeutic agents that have a low susceptibility to multiple mechanisms of tumor survival that can result in treatment failure. ${ }^{11-15}$ Currently, ixabepilone is the only epothilone to receive approval through the US Food and Drug Administration (FDA) for the treatment of patients with locally advanced or metastatic breast cancer in combination with capecitabine after failure of an anthracycline and a taxane, and as monotherapy after failure of an anthracycline, a taxane, and capecitabine. Similar to taxanes, epothilones like ixabepilone bind to $\beta$-tubulin and promote tubulin polymerization and microtubule stabilization, leading to cell cycle arrest and tumor cell apoptosis. ${ }^{16}$ However, epothilones may retain activity where taxanes fail, because they bind to $\beta$-tubulin in a qualitatively different manner than the taxanes. ${ }^{17,18}$ Importantly, ixabepilone retains activity in tumors that have upregulated their expression of the class III isotype of $\beta$-tubulin ( $\beta$ III-tubulin), ${ }^{19}$ a condition that has been linked to failure of other microtubule-targeting agents such as taxanes and vinca alkaloids. ${ }^{20,21}$ As a class, epothilones also induce apoptosis through multiple pathways that appear to be distinct for this class of agents, including enhancement of caspase-2 activity and p53-mediated activation of the death effector Bax. ${ }^{15}$ In contrast, taxanes induce apoptosis mainly through caspase 9 activation. ${ }^{15}$

Additionally, in preclinical studies with tumor cell models and xenografts, ixabepilone showed low susceptibility to several important cellular mechanisms that render multiple classes of therapy ineffective, including elevated expression of drug efflux transporter proteins (eg, P-glycoprotein and multiple-resistance protein-1). ${ }^{15}$

Clinically, ixabepilone has exhibited single-agent activity against a broad range of tumors, including breast cancer, nonsmall cell lung carcinoma, pancreatic cancer, renal cell cancer, prostate cancer, and lymphoma. ${ }^{15}$ Furthermore, as a single agent or in combination with capecitabine, ixabepilone has demonstrated clinical efficacy across the spectrum of breast cancer treatment in a number of studies. ${ }^{22-29}$ This article reviews the clinical evidence that supports the use of ixabepilone in the treatment of various stages of breast cancer.

\section{Ixabepilone in primary untreated breast cancer}

Neoadjuvant ixabepilone has been evaluated in primary untreated breast cancer in a phase II trial involving women with previously untreated, invasive, stage IIA-IIIB breast cancer $(n=164) .{ }^{22}$ Patients with tumors at least $3 \mathrm{~cm}$ in diameter were administered an intravenous (IV) infusion of ixabepilone at $40 \mathrm{mg} / \mathrm{m}^{2}$ over 3 hours on day 1 of a 21-day cycle for up to 4 cycles prior to surgery. Surgery was followed by anthracycline-based adjuvant chemotherapy, radiotherapy, or tamoxifen, as indicated. A pathologic complete response (pCR) in the breast was achieved in $18 \%$ $(29 / 161)$ of evaluable patients, with a higher response rate $(26 \% ; 11 / 42)$ in patients with tumors that were negative for the estrogen receptor (ER), progesterone receptor (PgR), and HER2 (ie, the so-called "triple-negative" patients). The pCR rates in the breast and axilla were $11 \%$ in all treated patients and $19 \%$ in the triple-negative subset.

Interestingly, a retrospective microarray analysis of tissue samples from patients from this study revealed that the triple-negative patients expressed higher levels of $\beta I I I-t u b u l i n$. Moreover, a receiver operating characteristics (ROC) analysis showed that, in the overall population, $\beta$ III-tubulin expression was predictive of response to ixabepilone. ${ }^{30}$ These results might partially explain the higher response in patients with triple-negative disease, although further characterization of this phenomenon is needed. In this neoadjuvant study, grade 3 or 4 neutropenia was reported by $13 \%$ of patients and grade 3 or 4 neuropathy by $2 \%$.

Although only limited conclusions can be drawn by comparing results from different studies, the $\mathrm{pCR}$ rates from this phase II trial compared favorably with those observed in trials of other regimens, which ranged from $3 \%$ to $20 \%$ (Table 1). ${ }^{22,31-35}$ Trials at several institutions are expanding the investigation of ixabepilone in patients with primary untreated breast cancer. For instance, in an ongoing phase II study, the efficacy and tolerability of neoadjuvant ixabepilone is being compared with paclitaxel when administered after doxorubicin and cyclophosphamide in patients with early breast cancer. $^{36}$

\section{Ixabepilone trials as an adjuvant therapy}

To date, there is no published data to support the use of ixabepilone in the adjuvant setting. A randomized, open-label, phase III trial is underway to evaluate the benefit of a sequential regimen of FEC 100 (5-fluorouracil, epirubicin, and cyclophosphamide) and ixabepilone in the adjuvant treatment of triple-negative or HER2- and PgR-negative node-positive or -negative breast cancer. ${ }^{37}$ Another ongoing phase III study is comparing single-agent ixabepilone with single-agent paclitaxel administered 
Table I Pathologic response rates in single-agent neoadjuvant phase II trials for early breast cancer $22,31-35$

\begin{tabular}{|c|c|c|c|c|c|}
\hline Reference & Patients, n & Treatment & Dose and schedule & Number of cycles & PCR, \% \\
\hline Baselga et $\mathrm{al}^{22}$ & 161 & Ixabepilone & $\begin{array}{l}40 \mathrm{mg} / \mathrm{m}^{2} \mathrm{IV} \text { over } 3 \text { hours; } \\
\text { every } 3 \text { weeks }\end{array}$ & 4 & 18 \\
\hline Fisher et $\mathrm{al}^{31}$ & 1523 & $\begin{array}{l}\text { Doxorubicin/ } \\
\text { cyclophosphamide }\end{array}$ & $\begin{array}{l}60 \text { and } 600 \mathrm{mg} / \mathrm{m}^{2} \text {, respectively; } \\
\text { schedule not reported }\end{array}$ & 4 & 13 \\
\hline Gradishar $^{32}$ & 33 & Docetaxel & $\begin{array}{l}100 \mathrm{mg} / \mathrm{m}^{2} \mathrm{IV} \text { over I hour; } \\
\text { every } 3 \text { weeks }\end{array}$ & 4 & 3 \\
\hline Buzdar et $\mathrm{al}^{33}$ & 87 & Paclitaxel & $\begin{array}{l}250 \mathrm{mg} / \mathrm{m}^{2} \mathrm{IV} \text { over } 24 \text { hours; } \\
\text { every } 3 \text { weeks }\end{array}$ & 4 & 9 \\
\hline Amat et $\mathrm{a}^{34}$ & 80 & Docetaxel & $\begin{array}{l}100 \mathrm{mg} / \mathrm{m}^{2} \mathrm{IV} \text { over I hour; } \\
\text { every } 3 \text { weeks }\end{array}$ & 6 & 20 \\
\hline Estévez et al ${ }^{35}$ & 56 & Docetaxel & $\begin{array}{l}40 \mathrm{mg} / \mathrm{m}^{2} \text { IV over } 30 \text { minutes; } \\
\text { weekly for } 6 \text { weeks of an 8-week cycle }\end{array}$ & 12 & 16 \\
\hline
\end{tabular}

Abbreviation: $\mathrm{PCR}$, pathologic complete response; IV, intravenous.

after doxorubicin and cyclophosphamide for the adjuvant treatment of triple-negative, early-stage breast cancer. ${ }^{38}$

\section{Ixabepilone in locally advanced and metastatic disease}

Ixabepilone has been evaluated in patients with locally advanced and metastatic breast cancer in a series of phase II trials ${ }^{23-27,39,40}$ (as a single agent [Table 2] ] $^{23-27}$ and in combination with various cytotoxic and targeted agents) and phase III trials (in combination with capecitabine)..$^{28,29}$

\section{Taxane-naïve patients}

Several studies have suggested that ixabepilone has significant antitumor activity in patients who have not received prior taxane therapy but have received prior anthracycline therapy. For example, Denduluri and colleagues evaluated the use of daily ixabepilone as a single agent in patients with metastatic breast cancer who had not received taxanes in the adjuvant or metastatic setting. ${ }^{23}$ This study placed no limits on prior therapy. Of the 23 patients enrolled in this study, $70 \%$ had received prior chemotherapy, including anthracyclines and/or capecitabine, and $61 \%$ of those with hormone receptor-positive disease had been treated with prior hormone therapy. Ixabepilone at $6 \mathrm{mg} / \mathrm{m}^{2}$ was administered as a 1-hour IV infusion on the first 5 consecutive days of a 21-day cycle until unacceptable toxic effects or disease progression occurred. Patients received between 2 and 22 treatment cycles (median, 8 cycles); four patients required dose reductions owing to adverse events. Thirteen patients achieved a partial response (PR), giving an objective response rate (ORR) of $57 \%$, with a median duration of response of 5.6 months. Another six patients (26\%) achieved stable disease (SD) for 6 weeks or more. Median time-to-progression (TTP) in all patients was 5.5 months. Of the five patients who received ixabepilone as first-line metastatic therapy, three achieved a PR and one had SD. Of the 12 patients who had received prior anthracyclines, seven had a PR and four had SD. Treatment was generally well tolerated, with most adverse events being mild or moderate in severity. Grade 3 and 4 adverse events included fatigue $(13 \%)$, nausea $(9 \%)$, motor neuropathy $(4 \%)$, and neutropenia $(22 \%)$.

Roché and associates examined the use of first-line ixabepilone monotherapy at $40 \mathrm{mg} / \mathrm{m}^{2}$ as a 3-hour IV infusion on day 1 of a 21-day cycle among 65 patients with metastatic breast cancer pretreated with adjuvant anthracyclines. ${ }^{26}$ Although patients were receiving first-line treatment for metastatic disease, they had an extensive tumor burden; most had involvement of at least two tumor sites (77\%) and/or visceral metastases $(85 \%)$. Twenty-seven patients achieved a PR, producing an ORR of $41.5 \%$, with a median duration of 8.2 months. SD occurred in 23 patients (35\%), 11 of whom were progression free for at least 6 months. In the total study population, median TTP was 4.8 months, and median overall survival (OS) was 22 months. It should be noted that although no patients had received taxanes for metastatic disease, $17 \%$ of patients had been exposed to taxanes as part of an adjuvant regimen. No analysis of response based on prior taxane exposure was reported. Treatment-related adverse events were mostly grade 1 or 2 in severity and included alopecia (92\%), sensory neuropathy (71\%), fatigue (68\%), myalgia (65\%), and nausea (54\%). Hematologic toxicities did not result in treatment discontinuation or death, with only 7 patients requiring a delay in dosing. The main grade 3 and 4 toxicities included sensory neuropathy (20\%), neutropenia (58\%), and leukopenia (50\%). 


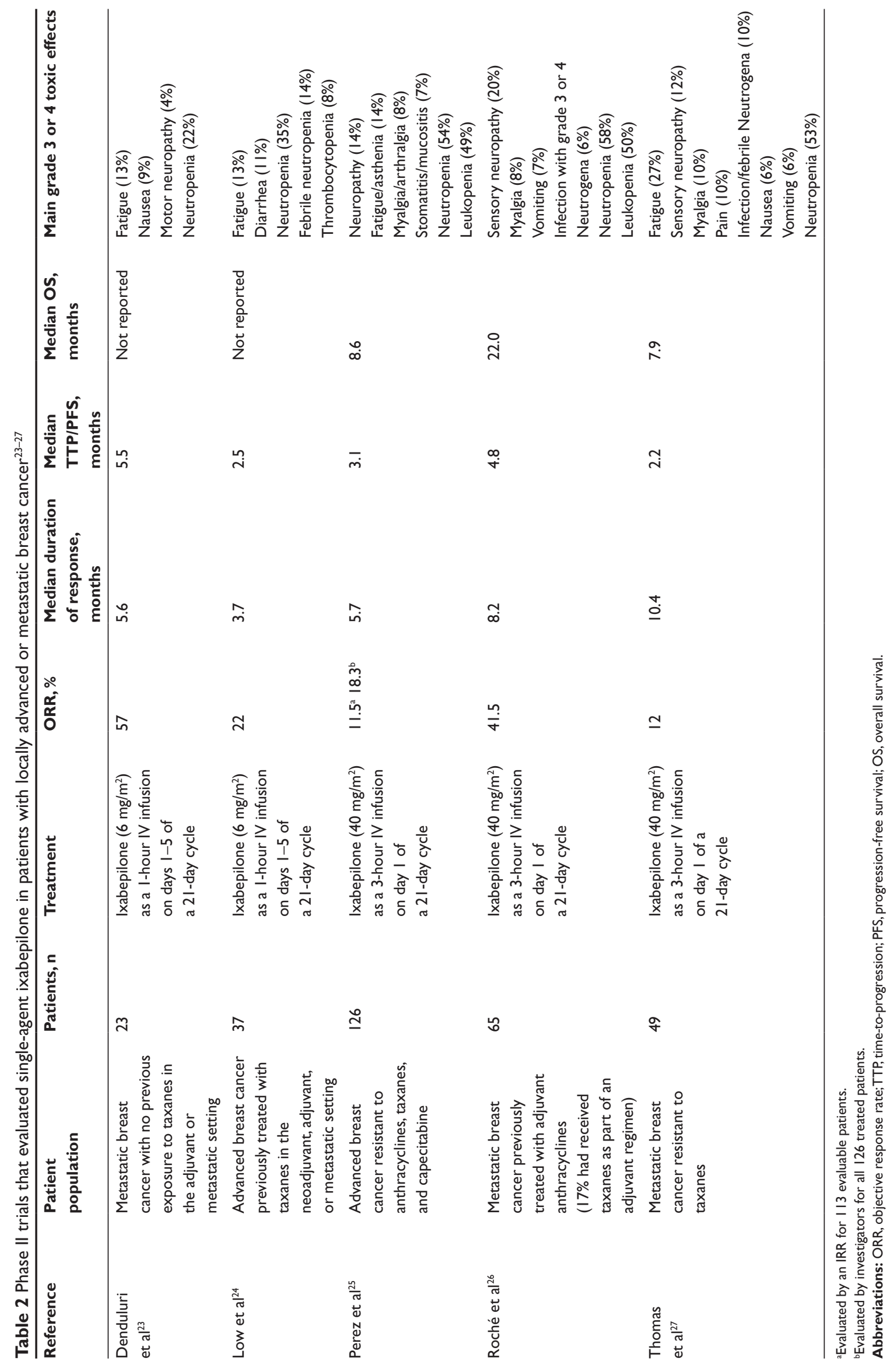


Although these phase II monotherapy studies involved small sample sizes and did not include a control arm, the observed response rates and survival outcomes with ixabepilone are encouraging for the treatment of patients with prior exposure to anthracyclines, even among those with an extensive tumor burden.

Clinicians will be inclined to ask how ixabepilone performs in comparison to the taxanes, therefore broad comparisons between separate trials suggest that the results with ixabepilone are similar to outcomes achieved in phase III studies that evaluated docetaxel or paclitaxel in patients with advanced breast cancer that has progressed during anthracycline therapy (ORRs, $25 \%$ to $59 \%$; TTP/PFS, 3.6 to 19.0 months; OS durations, 11.4 to 34.0 months) ${ }^{41-43} \mathrm{In}$ addition, a recent phase II trial suggests that, like paclitaxel, ixabepilone is also effective given on a weekly basis $\left(15 \mathrm{mg} / \mathrm{m}^{2}\right)$ with trastuzumab $(2 \mathrm{mg} / \mathrm{kg}$, after a $4 \mathrm{mg} / \mathrm{kg}$ loading dose) and carboplatin (area under curve [AUC], 2) as first-line therapy in HER2-positive patients. ${ }^{39}$ Among 59 treated patients, $44 \%$ achieved an objective response; median TTP and OS were 8.2 months and 34.7 months, respectively. These results are comparable to phase III outcomes for the combination of every-3-week paclitaxel and carboplatin plus weekly trastuzumab (ORR, 52\%; PFS, 10.7 months; OS, 35.7 months),${ }^{44}$ even though approximately one-third of patients in the ixabepilone trial had received taxanes in the neoadjuvant or adjuvant setting compared to none in the paclitaxel trial.

Data directly comparing ixabepilone to the taxanes in the first-line setting has only recently become available, when a randomized phase II study evaluated the combination of ixabepilone and bevacizumab at two doses and schedules (ixabepilone $16 \mathrm{mg} / \mathrm{m}^{2}$ on days 1,8 , and 15 plus bevacizumab $10 \mathrm{mg} / \mathrm{kg}$ every 2 weeks [ $\mathrm{n}=46$ ] or ixabepilone $40 \mathrm{mg} / \mathrm{m}^{2}$ plus bevacizumab $15 \mathrm{mg} / \mathrm{kg}$ every 3 weeks [n =45]) in comparison to paclitaxel $\left(90 \mathrm{mg} / \mathrm{m}^{2}\right.$ on days 1,8 , and 15$)$ plus bevacizumab $(10 \mathrm{mg} / \mathrm{kg}$ every 2 weeks $[n=32]$ ) as first-line therapy for metastatic breast cancer. ${ }^{40}$ Although the numbers of patients in each arm were small, efficacy outcomes for both the weekly (ORR, 50\%; 24-week PFS, 75\%) and the every-3-week (ORR, 71\%; 24week PFS, 86\%) ixabepilone regimens appeared to be at least comparable to those seen with weekly paclitaxel (ORR, 56\%; 24-week PFS, 94\%) when combined with bevacizumab. Toxicity profiles were also similar, although rates of grade $3 / 4$ neutropenia were higher for every-3-week ixabepilone (55\%) than for weekly ixabepilone (11\%) or paclitaxel $(22 \%) .{ }^{40}$ Results from an ongoing phase III trial may provide a more definitive comparison of these regimens (CALGB 40502; NCT00785291).

\section{Patients with prior exposure to taxanes}

Options for second and subsequent lines of chemotherapy for metastatic breast cancer are especially limited for patients with innate or acquired taxane resistance. Single-agent ixabepilone has proven effective as a second-, third-, or fourthline option in heavily-pretreated and multidrug-resistant patients. In a registrational study conducted for FDA approval, Perez and coworkers evaluated ixabepilone at $40 \mathrm{mg} / \mathrm{m}^{2}$ as a 3-hour IV infusion on day 1 of every 21-day cycle in 126 patients with anthracycline-, taxane-, and/or capecitabineresistant metastatic breast cancer. ${ }^{25}$ Patients had baseline disease characteristics that included multiple disease sites and visceral disease affecting the liver and lung. In addition, one-third of patients had triple-negative disease. Despite the poor prognosis of the population as a whole, $11.5 \%$ of 113 evaluable patients achieved an independent radiology review (IRR)-assessed objective response, with a median duration of response of 5.7 months. In addition, $50 \%$ of patients achieved IRR-assessed SD with median PFS and OS durations of 3.1 months and 8.6 months, respectively. Grade 3 and 4 nonhematologic adverse events included peripheral sensory neuropathy (14\%) and fatigue/asthenia (14\%). In most instances, neuropathy occurred early on in treatment and was generally reversible with dose reductions within a median time of 5.4 weeks. ${ }^{45}$ Grade 3 or 4 neutropenia and leukopenia occurred in $54 \%$ and $49 \%$ of patients, respectively, but febrile neutropenia and infection were uncommon (reported in 4 and 3 patients, respectively). ${ }^{25}$

Low and colleagues determined the efficacy and tolerability of ixabepilone in 37 women with locally advanced or metastatic breast cancer previously treated with taxanes in the neoadjuvant, adjuvant, or metastatic setting. ${ }^{24}$ At baseline, patients were heavily pretreated, with $43 \%$ having received between three and nine prior chemotherapy regimens for metastatic disease and all patients having received at least two cycles of a paclitaxel- or docetaxel-containing regimen. Ixabepilone was administered as a 1-hour IV infusion of $6 \mathrm{mg} / \mathrm{m}^{2}$ on the first 5 consecutive days of a 21-day cycle until unacceptable toxic effects or disease progression occurred. One patient achieved a pCR and seven achieved a PR for an ORR of $22 \%$, with median response duration of 3.7 months. Another $35 \%$ of patients achieved SD for $\geq 6$ weeks. Interestingly, the SD responses were achieved in patients who had experienced disease progression while receiving taxanes and in patients who had been previously treated with doxorubicin, capecitabine, and a taxane, suggesting that ixabepilone was able to circumvent tumor resistance mechanisms in these patients. In the entire study population, median TTP was 
2.5 months. Grade 3 and 4 toxicities included neutropenia (35\%), febrile neutropenia (14\%), fatigue (14\%), diarrhea (11\%), nausea/vomiting (5\%), myalgia/arthralgia (3\%), and sensory neuropathy $(3 \%)$. One patient withdrew from the study because of grade 3 sensory neuropathy, and one patient withdrew because of prolonged grade 2 sensory neuropathy.

Thomas and colleagues investigated the use of ixabepilone in patients with metastatic breast cancer that had progressed during, or within 4 months of taxane therapy (6 months if received in the adjuvant setting). ${ }^{27}$ In this study, 49 patients were administered ixabepilone at $40 \mathrm{mg} / \mathrm{m}^{2}$ as a 3-hour IV infusion on day 1 of a 21-day cycle. Patients were heavily pretreated $(86 \%$ had received two or more prior chemotherapy regimens) and had a substantial tumor burden $(84 \%$ had at least two involved disease sites, and $84 \%$ had visceral disease). The ORR was 12\% (6 PRs), with a median duration of response of 10.4 months. All responders had extensive disease at baseline that had progressed after multiple prior therapies. Forty-one percent of patients achieved SD, with a median TTP of 2.2 months and median OS of 7.9 months. Most adverse events were mildto-moderate in severity. The most common adverse events of any grade included fatigue (76\%), nausea (57\%), pain (65\%), and sensory neuropathy (all grades, 63\%; grade 3 , $12 \%$; grade $4,0 \%$ ). Sensory neuropathy was largely reversible and responsive to ixabepilone dose reductions.

A combination of ixabepilone plus capecitabine has also been studied in patients with metastatic breast cancer previously treated with anthracyclines or a taxane..$^{28,29}$ Promising efficacy and safety results from a phase I/II trial ${ }^{46}$ led to initiation of a pivotal phase III trial (BMS 046) of ixabepilone $\left(40 \mathrm{mg} / \mathrm{m}^{2}\right.$ as a 3 -hour IV infusion on day 1 every 21 days) plus capecitabine $\left(2000 \mathrm{mg} / \mathrm{m}^{2}\right.$ on days 1 to 14 of a 21-day cycle) compared with capecitabine alone ( $2500 \mathrm{mg} / \mathrm{m}^{2}$ on days 1 to 14 of a 21 -day cycle) in 752 patients with locally advanced or metastatic breast cancer that had progressed after treatment with anthracyclines and taxanes. ${ }^{28}$ In its entrance criteria, the study employed a strict definition of taxane resistance, requiring patients to have progressed during treatment or relapsed within 4 months of the last dose in the metastatic setting or within 12 months in the adjuvant setting. In general, patients were heavily pretreated and had a heavy burden of disease; nearly $50 \%$ of patients had received $\geq 2$ prior regimens in the metastatic setting, $90 \%$ of patients had metastases at two or more sites, and $84 \%$ had visceral disease involving the liver and/or lung. In this study, adding ixabepilone to capecitabine achieved an IRR-assessed ORR of $35 \%$ compared with $14 \%$ for capecitabine monotherapy, and an investigator-assessed ORR of $42 \%$ compared with $23 \%$ for capecitabine monotherapy. Median durations of response for the two treatment arms were 6.4 and 5.6 months, respectively. The median IRR-assessed PFS was significantly longer for the combined regimen (5.8 months) than for capecitabine alone (4.2 months), resulting in a $25 \%$ risk reduction for disease progression with combined therapy (hazard ratio [HR], 0.75; 95\% confidence interval [CI], 0.64 to $0.88 ; P=0.003$; Figure 1$).{ }^{28}$ Consistent with this result, the investigator-assessed median PFS was longer for the combined regimen than for capecitabine alone (5.3 vs 3.8 months; $P=0.0011$ ). This improvement in disease progression was maintained in a sensitivity analysis requested by the FDA. When patients who received subsequent therapy before disease progression were censored for PFS at the last tumor assessment date, ixabepilone plus capecitabine still prolonged PFS compared with capecitabine alone (5.7 vs 4.1 months; HR, 0.69 ; 95\% CI, 0.58 to $0.83 ; P<0.0001) .{ }^{47}$ Compared with capecitabine alone, ixabepilone plus capecitabine was associated with a higher rate of grade 3 or 4 sensory neuropathy $(21 \%$ vs $0 \%)$, fatigue ( $9 \%$ vs $3 \%$ ), and neutropenia $(68 \%$ vs $11 \%$ ), as well as an increased rate of neutropenia-related death as a result of toxicity ( $3 \%$ vs $1 \%$, with patients with liver dysfunction [ $\geq$ grade 2 liver function tests] at greater risk). ${ }^{28}$

A larger confirmatory phase III trial (BMS 048) in patients who were pretreated and/or resistant to anthracyclines and taxanes $(n=1221)$ provided further evidence that ixabepilone plus capecitabine consistently improved PFS compared with capecitabine alone (6.2 vs 4.4 months). ${ }^{29}$ Notably, $50 \%$ of the

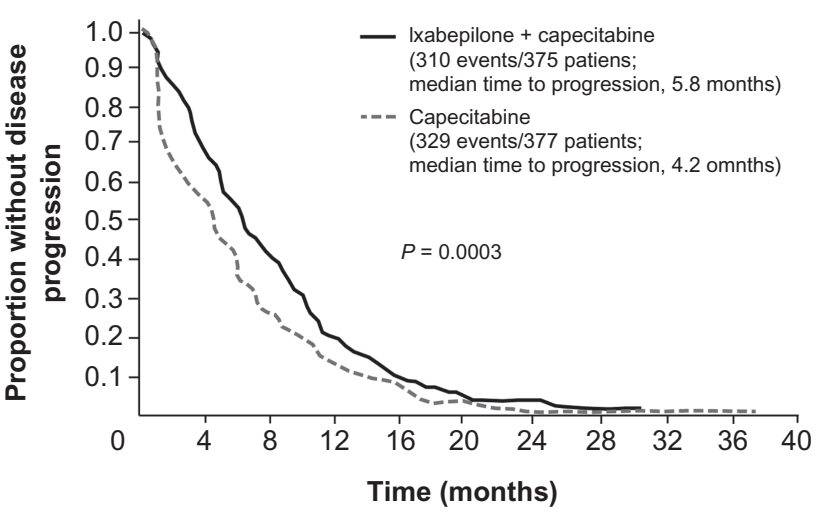

Figure I Independent radiology review-assessed PFS durations after treatment with ixabepilone plus capecitabine compared with capecitabine alone in women with locally advanced or metastatic breast cancer that had progressed after anthracycline and taxane treatment. ${ }^{28}$ Copyright (C) 2007. Reproduced with permission from Thomas ES, Gomez HL, Li RK, et al. Ixabepilone plus capecitabine for metastatic breast cancer progressing after anthracycline and taxane treatment.J Clin Oncol. 2007;25:5210-52 17. 
patients in the confirmatory trial met the resistance criteria utilized in the pivotal trial.

Neither phase III study showed a significant difference in median OS between the two treatment arms; however, adjusting for prognostic factors in a preplanned analysis, combination therapy significantly reduced the risk of death by about $15 \%$ ( $P=0.0803$ for BMS 046; $P=0.0231$ for BMS 048). ${ }^{29}$ Furthermore, as a part of these phase III studies, prospectively defined subset analyses revealed statistically significant improvements in PFS when the combination of ixabepilone and capecitabine was used as first-line metastatic therapy (after having received anthracyclines and/or taxanes in the adjuvant setting) and in triple-negative patients. ${ }^{48-50}$ Patients who received ixabepilone plus capecitabine as first-line therapy experienced a 54\% reduction in the estimated risk of disease progression with combination therapy. ${ }^{48}$ Taken together, these results showed that ixabepilone in combination with capecitabine has superior clinical efficacy to capecitabine alone in patients with metastatic disease pretreated or resistant to anthracyclines and resistant to taxanes, a population with limited effective treatment options.

\section{Safety and tolerability of ixabepilone}

Ixabepilone has a manageable safety profile in patients with all stages of breast cancer, even in those with extensive or heavily pretreated disease (Table 3 ). ${ }^{23-28}$ As mentioned, neutropenia, sensory neuropathy, fatigue, arthralgias, myalgias, and stomatitis are the main toxic effects associated with this agent. ${ }^{22-29,46}$ Ixabepilone-related adverse events are usually manageable through dose reductions or delays or with supportive care. Importantly, the toxicity profile of ixabepilone does not appear to overlap with that of capecitabine, ${ }^{28,29}$ bevacizumab, ${ }^{40}$ or trastuzumab. ${ }^{39}$

Currently, the approved dose and schedule of ixabepilone (as monotherapy or with capecitabine) is $40 \mathrm{mg} / \mathrm{m}^{2}$ administered IV every 3 weeks. Ongoing studies are evaluating the clinical profile of ixabepilone when administered weekly. An interim safety analysis of one such study, a randomized phase II trial comparing ixabepilone at the approved dose and schedule to ixabepilone $16 \mathrm{mg} / \mathrm{m}^{2}$ given on days 1,8 , and 15 of a 28-day cycle, suggested that although both schedules were well tolerated among patients (all had advanced metastatic breast cancer and three-quarters had received prior therapy in the metastatic setting), the weekly schedule was associated with a lower overall incidence of adverse events, particularly grade $3 / 4$ peripheral neuropathy. ${ }^{51}$
Although neutropenia is frequently associated with ixabepilone therapy, the rate of febrile neutropenia is generally low. Hematologic toxicity is easily managed by dose reduction or by use of hematologic growth factors, but ixabepilone should not be administered until neutrophil counts are at least 1,500 cells $/ \mathrm{mm}^{3}$ and platelet counts at least 100,000 cells $/ \mathrm{mm}^{3} .{ }^{32}$ Furthermore, in the initial phase III trial of ixabepilone plus capecitabine, a higher rate of neutropenia-related deaths was reported in the combination-therapy group, particularly in patients with pre-existing hepatic insufficiency, than in the capecitabine-alone group. ${ }^{28}$ For this reason, ixabepilone in combination with capecitabine is contraindicated in patients with signs of moderate-to-severe liver dysfunction at baseline..$^{52}$

Neurotoxicity is a major concern with microtubulestabilizing drugs like taxanes, ${ }^{53,54}$ and in clinical trials with locally advanced or metastatic breast cancer, the rates of grade 3 and 4 peripheral sensory neuropathy with ixabepilone therapy ranged from $0 \%$ to $21 \%$ (Table 3 ). Neuropathy was mainly sensory, cumulative, and reversible upon treatment modification or delay. ${ }^{54}$ For example, in the initial phase III study of ixabepilone plus capecitabine, 70 of the 79 patients with grade 3 or 4 peripheral neuropathy had complete resolution or improvement of symptoms, with a median time to resolution to grade 1 or baseline severity of 6 weeks (Figure 2). ${ }^{54}$ In patients with grade 2 peripheral neuropathy lasting $\geq 7$ days, the dose of ixabepilone should be reduced by $20 \%$. Patients with grade 3 neuropathy lasting $<7$ days should also receive a $20 \%$ reduction in the dose of ixabepilone. Ixabepilone should be discontinued in patients who experience grade 3 neuropathy lasting $\geq 7$ days or disabling neuropathy. ${ }^{52}$ In the initial phase III study of ixabepilone plus capecitabine, patients with persistent grade 2 or 3 peripheral neuropathy received a median of three additional cycles after dose reduction. After dose reduction, peripheral neuropathy either improved or stabilized in most patients. ${ }^{28}$ Neurologic function tests may be of some value in predicting the risk of sensory neuropathy during ixabepilone therapy. ${ }^{55}$

As with any chemotherapeutic agent, the benefits associated with ixabepilone therapy should be carefully weighed against the risks. In the setting of locally advanced or metastatic breast, a positive benefit-to-risk profile for combination ixabepilone plus capecitabine was revealed in a quality adjusted time without symptoms or toxicities (Q-TWiST) analysis of the initial phase III trial. ${ }^{56}$ This Q-TWiST analysis evaluated the trade-off between 
Table 3 Adverse events that occurred in $\geq 10 \%$ of clinical trials of ixabepilone for locally advanced or metastatic breast cancer ${ }^{23-28}$

\begin{tabular}{|c|c|c|c|c|c|c|c|}
\hline Study & Thomas et al ${ }^{28}$ & & Denduluri et $\mathbf{a l}^{23}$ & Roché et $\mathbf{a l}^{26}$ & Low et a $\left.\right|^{24}$ & Thomas et $\mathbf{a l}^{27}$ & Perez et $\mathrm{a}^{25}$ \\
\hline Dose/schedule & $\begin{array}{l}\text { Ixabepilone } \\
40 \mathrm{mg} / \mathrm{m}^{2} \\
\text { every } 3 \text { weeks + } \\
\text { capecitabine } \\
2000 \mathrm{mg} / \mathrm{m}^{2} \\
\text { on days I-14 }\end{array}$ & $\begin{array}{l}\text { Capecitabine } \\
2500 \mathrm{mg} / \mathrm{m}^{2} \text { on } \\
\text { days } \mathrm{I}-14\end{array}$ & $\begin{array}{l}\text { Ixabepilone } \\
6 \mathrm{mg} / \mathrm{m}^{2} \text { daily } \\
\text { on days I-5 } \\
\text { every } 3 \text { weeks }\end{array}$ & $\begin{array}{l}\text { Ixabepilone } \\
40 \mathrm{mg} / \mathrm{m}^{2} \\
\text { every } 3 \text { weeks }\end{array}$ & $\begin{array}{l}\text { Ixabepilone } \\
40 \mathrm{mg} / \mathrm{m}^{2} \\
\text { every } 3 \text { weeks }\end{array}$ & $\begin{array}{l}\text { Ixabepilone } \\
40 \mathrm{mg} / \mathrm{m}^{2} \\
\text { every } 3 \text { weeks }\end{array}$ & $\begin{array}{l}\text { Ixabepilone } \\
40 \mathrm{mg} / \mathrm{m}^{2} \\
\text { every } \\
3 \text { weeks }\end{array}$ \\
\hline $\begin{array}{l}\text { Number of patients } \\
\text { treated }\end{array}$ & 369 & 368 & 23 & 65 & 37 & 49 & 126 \\
\hline Patient population & \multicolumn{2}{|c|}{$\begin{array}{l}\text { Pretreated; resistant to } \\
\text { anthracyclines } \\
\text { and resistant to taxanes }\end{array}$} & $\begin{array}{l}\text { No previous } \\
\text { exposure to } \\
\text { taxanes in } \\
\text { adjuvant } \\
\text { or metastatic } \\
\text { setting }\end{array}$ & $\begin{array}{l}\text { Previously treated } \\
\text { with adjuvant } \\
\text { anthracyclines }\end{array}$ & $\begin{array}{l}\text { Previously } \\
\text { treated } \\
\text { with taxanes in } \\
\text { neoadjuvant, } \\
\text { adjuvant, or } \\
\text { metastatic } \\
\text { setting }\end{array}$ & $\begin{array}{l}\text { Resistant to } \\
\text { taxanes }\end{array}$ & $\begin{array}{l}\text { Resistant to } \\
\text { anthracy- } \\
\text { clines, } \\
\text { taxanes, and } \\
\text { capecitabine }\end{array}$ \\
\hline \multicolumn{8}{|c|}{ Nonhematologic adverse events, $\%$ all grades (\% grade $3 / 4$ ) } \\
\hline $\begin{array}{l}\text { Peripheral sensory } \\
\text { neuropathy }\end{array}$ & $64(21)$ & $16(0)$ & $52(0)$ & $71(20)$ & $54(3)$ & $63(12)$ & $60(14)$ \\
\hline Fatigue/asthenia & $64(16)$ & $30(4)$ & $78(13)$ & $68(6)$ & $65(14)$ & $76(27)$ & $50(14)$ \\
\hline Myalgia/arthralgia & 53 & 6 & 30 & 97 & 51 & 84 & 49 \\
\hline Alopecia & 31 & 3 & 87 & 92 & 54 & 43 & 48 \\
\hline Nausea & 53 & 40 & 61 & 54 & 54 & 57 & 42 \\
\hline $\begin{array}{l}\text { Stomatitis/mucositis/ } \\
\text { pharyngitis }\end{array}$ & 33 & 21 & - & 32 & - & 28 & 29 \\
\hline Vomiting & 39 & 24 & 39 & 26 & 22 & 41 & 29 \\
\hline Diarrhea & 44 & 39 & 48 & 29 & 35 & 31 & 22 \\
\hline Rash & - & - & - & 22 & - & 12 & - \\
\hline Musculoskeletal pain & - & - & - & - & - & - & 20 \\
\hline Anorexia & 31 & 14 & - & 18 & - & 18 & 19 \\
\hline Constipation & 22 & 6 & 56 & 20 & 27 & 20 & 16 \\
\hline Nail changes & 20 & 8 & 56 & 17 & 30 & 8 & 9 \\
\hline Fever & - & - & - & 14 & - & 16 & - \\
\hline $\begin{array}{l}\text { Abdominal pain/ } \\
\text { cramping }\end{array}$ & - & - & - & 8 & - & 10 & 13 \\
\hline Headache & - & - & - & 14 & - & - & 11 \\
\hline Neuropathic pain & - & - & - & 12 & - & 8 & - \\
\hline Pain, other & - & - & - & 14 & - & 65 & 8 \\
\hline $\begin{array}{l}\text { Infection without } \\
\text { neutropenia }\end{array}$ & - & - & - & 14 & - & 12 & - \\
\hline $\begin{array}{l}\text { Infection/febrile } \\
\text { neutropenia }\end{array}$ & - & - & 0 & 6 & 14 & 6 & - \\
\hline Motor neuropathy & 16 & 0.3 & 9 & 6 & - & - & 10 \\
\hline $\begin{array}{l}\text { Taste disturbance/ } \\
\text { dysgeusia }\end{array}$ & $=$ & $=$ & 65 & 11 & 32 & - & 6 \\
\hline Hand-foot syndrome & 64 & 62 & - & - & - & - & - \\
\hline \multicolumn{8}{|c|}{ Hematologic adverse events, $\%$ all grades (\% grade $3 / 4$ ) } \\
\hline Neutropenia & $89(67)$ & $43(\mathrm{II})$ & $87(22)$ & $89(58)$ & $68(35)$ & N/A (53) & $79(54)$ \\
\hline Leukopenia & $90(57)$ & $54(6)$ & - & $92(50)$ & - & $6(2)$ & $90(49)$ \\
\hline Anemia & $90(9)$ & $70(4)$ & $83(0)$ & $92(3)$ & $73(0)$ & $6(4)$ & $84(8)$ \\
\hline Thrombocytopenia & $54(8)$ & $31(4)$ & $52(4)$ & $40(0)$ & $4 \mid(8)$ & - & $44(8)$ \\
\hline
\end{tabular}




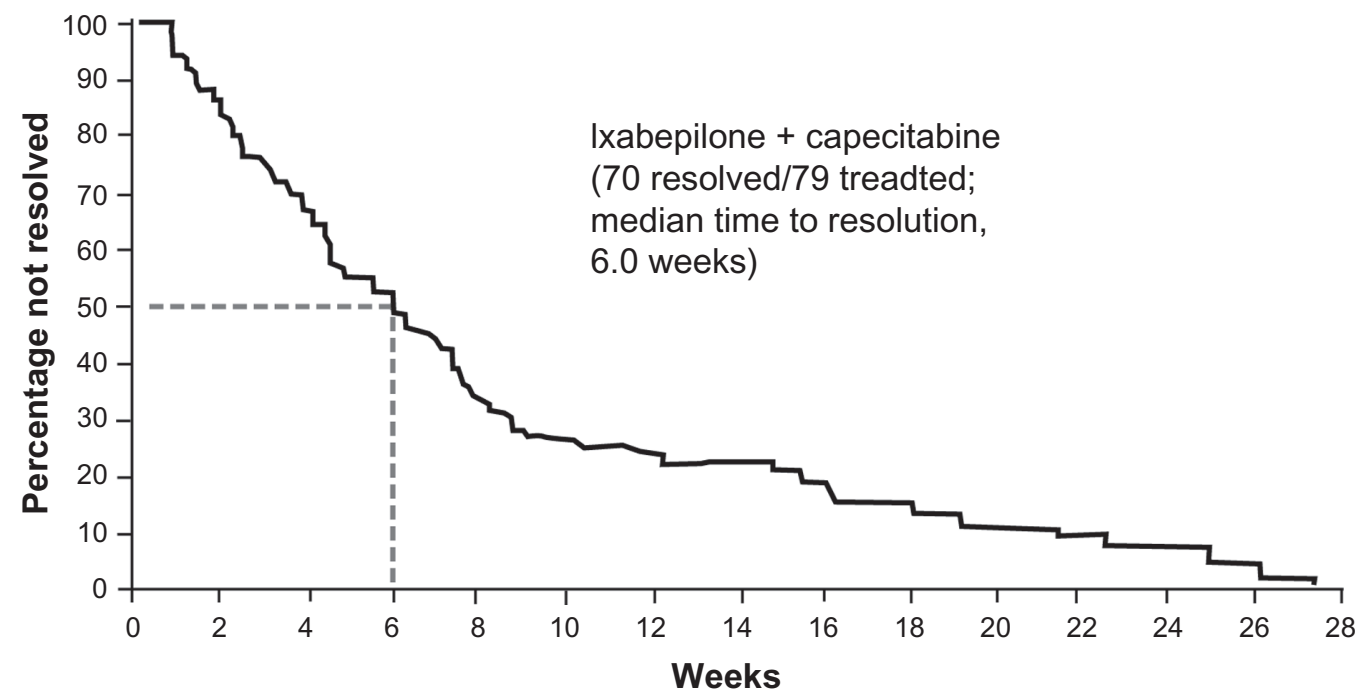

Figure 2 Resolution of grade 3 or 4 peripheral neuropathy in patients who received ixabepilone plus capecitabine..$^{54}$ Copyright $@ 2008$.

Reproduced with permission from Swain SM,Arezzo JC. Neuropathy associated with microtabile-stabilzing agents. Clin Adv Hematol Oncol. 2008;6:455-467.

toxicity and PFS by taking into account the time spent by each patient with or without grade 3 or 4 toxicity prior to progression and the time from progression to death or end of follow-up. Remarkably, quality adjusted mean survival was significantly greater for ixabepilone plus capecitabine than it was for capecitabine alone $(P=0.0227)$, with a 3.8-week improvement with ixabepilone plus capecitabine over capecitabine alone.

\section{Conclusions}

The novel chemotherapeutic agent ixabepilone exhibits reduced susceptibility to several important tumor survival mechanisms that limit the efficacy of taxanes and anthracyclines. Ixabepilone has demonstrated efficacy in patients across the breast cancer spectrum of early-stage to advanced disease, including patients with extensive, aggressive, and heavily pretreated tumors and those with resistance to several other agents. Ixabepilone is approved for the treatment of patients with locally advanced or metastatic breast cancer as monotherapy after failure of an anthracycline, a taxane, and capecitabine, and in combination with capecitabine after failure of an anthracycline and a taxane. Ixabepilone is also being investigated in combinations with several other cytotoxic and biologic agents, and preliminary studies point toward efficacy in combination with bevacizumab or trastuzumab that is comparable to that of paclitaxel.

Preliminary data also suggest promising efficacy with ixabepilone in the neoadjuvant setting, and studies are underway investigating the benefits of ixabepilone in the adjuvant setting. The fact that $\beta$ III-tubulin appears to be particularly upregulated in triple-negative breast tumors may render ixabepilone more active in this subgroup of patients, an observation in need of additional clinical validation.

The manageable safety profile of ixabepilone supports its clinical utility, as adverse events can usually be managed with a dose reduction or delay, or with appropriate supportive care. Response appeared to be better and toxic effects were milder when ixabepilone was used earlier in the treatment course (eg, in the first- or second-line setting) in patients who were less heavily pretreated.

The phase III studies reveal that capecitabine does not exacerbate ixabepilone-related toxicities, or vice versa. Moreover, adverse events were manageable and responsive to intervention regardless of whether ixabepilone was given alone or with capecitabine. However, as is to be expected with any cytotoxic chemotherapy, the incidence and severity of toxicities was lower when ixabepilone was used as monotherapy. These observations highlight the need to evaluate candidates for ixabepilone therapy on a case-by-case basis to determine whether the patient may experience the greatest overall benefit from monotherapy or from more aggressive combination therapy. Importantly, ixabepilone still demonstrated reasonable efficacy when used as monotherapy, even in patients with a heavy disease burden, documented resistance to several other classes of chemotherapy, or aggressive tumors (eg, triple-negative disease). 
For the reasons discussed above, ixabepilone represents a clinically useful addition to the therapeutic agents available for patients with resistant advanced breast cancer that help to extend PFS in patients with limited treatment options. Ongoing investigations in early-stage disease should provide insight as to how this novel agent could be effectively integrated into this setting.

\section{Acknowledgment}

The author takes full responsibility for the content of this publication and confirms that it reflects his viewpoint and medical expertise. He also wishes to acknowledge StemScientific, funded by Bristol-Myers Squibb, for providing writing and editing support. Bristol-Myers Squibb did not influence the content of the manuscript, nor did the author receive financial compensation for authoring the manuscript.

\section{References}

1. O'Shaughnessy J, Miles D, Vukelja S, et al. Superior survival with capecitabine plus docetaxel combination therapy in anthracyclinepretreated patients with advanced breast cancer: phase III trial results. J Clin Oncol. 2002;20:2812-2823.

2. Melemed AS, O'Shaughnessy J, Nag S, et al. Phase III study of gemcitabine plus paclitaxel compared with paclitaxel alone in patients with unrespectable, locally recurrent, or metastatic breast cancer [abstract]. Presented at the 2007 ASCO Breast Cancer Symposium; 2007 Sep 7-8; San Francisco, CA, USA.

3. Martin M, Ruiz A, Muñoz M, et al. Spanish Breast Cancer Research Group (GEICAM) trial. Gemcitabine plus vinorelbine versus vinorelbine monotherapy in patients with metastatic breast cancer previously treated with anthracyclines and taxanes: final results of the phase II Spanish Breast Cancer Research Group (GEICAM) trial. Lancet Oncol. 2007;8:219-225.

4. Geyer CE, Forster J, Lindquist D, et al. Lapatinib plus capecitabine for HER2-positive advanced breast cancer. $N$ Engl J Med. 2006;355: 2733-2743.

5. von Minckwitz G, Zielinski C, Maarteense E, et al. Capecitabine versus capecitabine plus trastuzumab in patients with HER2-positive metastatic breast cancer progressing during trastuzumab treatment: the TBP phase III study (GBG 26/BIG 3-05) [abstract]. J Clin Oncol. 2008;26(Suppl):47S.

6. Miller KD, Wang M, Gralow J, et al. Paclitaxel plus bevacizumab versus paclitaxel alone for metastatic breast cancer. $N$ Engl $J$ Med. 2007;357:2666-2676.

7. Miles D, Chan A, Romieu G, et al. Randomized, double-blind, placebo-controlled, phase III study of bevacizumab with docetaxel or docetaxel with placebo as first-line therapy for patients with locally recurrent or metastatic breast cancer (mBC): AVADO [abstract]. J Clin Oncol. 2008;26(Suppl):1008S.

8. Ferlini C, Raspaglio G, Cicchillitti L, et al. Looking at resistance mechanisms for microtubule interacting drugs: does TUBB3 work? Curr Cancer Drug Targets. 2007;7:704-712.

9. Chien AJ, Moasser MM. Cellular mechanisms of resistance to anthracyclines and taxanes in cancer: intrinsic and acquired. Semin Oncol. 2008;35(Suppl 2):S1-S14.

10. Gonzalez-Angulo AM, Morales-Vasquez F, Hortobagyi GN. Overview of resistance to systemic therapy in patients with breast cancer. $A d v$ Exp Med Biol. 2007;608:1-22.
11. Goodin S, Kane MP, Rubin EH. Epothilones: mechanism of action and biological activity. J Clin Oncol. 2004;22:2015-2025.

12. Lee JJ, Swain SM. Development of novel chemotherapeutic agents to evade the mechanisms of multidrug resistance (MDR). Semin Oncol. 2005;32(Suppl 7):S22-S26.

13. Pivot X, Dufresne A, Villanueva C. Efficacy and safety of ixabepilone, a novel epothilone analogue. Clin Breast Cancer. 2007;7: $543-549$.

14. Goodin S. Novel cytotoxic agents: epothilones. Am J Health Syst Pharm. 2008;65(Suppl 3):S10-S15.

15. Vahdat L. Ixabepilone: a novel antineoplastic agent with low susceptibility to multiple tumor resistance mechanisms. Oncologist. 2008:13:214-221.

16. Bode CJ, Gupta ML Jr, Reiff EA, Suprenant KA, Georg GI, Himes RH. Epothilone and paclitaxel: unexpected differences in promoting the assembly and stabilization of yeast microtubules. Biochemistry. 2002;41:3870-3874.

17. Cortes J, Baselga J. Targeting the microtubules in breast cancer beyond taxanes: the epothilones. Oncologist. 2007;12:271-280.

18. Nettles JH, Li H, Cornett B, Krahn JM, Snyder JP, Downing KH. The binding mode of epothilone A on alpha, beta-tubulin by electron crystallography. Science. 2004;305:866-869.

19. Lee FYF, Smykla R, Johnston K, et al. Preclinical efficacy spectrum and pharmacokinetics of ixabepilone. Cancer Chemother Pharmacol. 2009;63:201-212.

20. Paradiso A, Mangia A, Chiriatti A, et al. Biomarkers predictive for clinical efficacy of taxol-based chemotherapy in advanced breast cancer. Ann Oncol. 2005;16(Suppl 4):iv14-iv19.

21. Sève $P$, Isaac $S$, Trédan $O$, et al. Expression of class III $\beta$-tubulin is predictive of patient outcome in patients with non-small cell lung cancer receiving vinorelbine-based therapy. Clin Cancer Res. 2005; 11: 5481-5486.

22. Baselga J, Zambetti M, Llombart-Cussac A, et al. Phase II genomics study of ixabepilone as neoadjuvant treatment for breast cancer. J Clin Oncol. 2009;27:526-534.

23. Denduluri N, Low JA, Lee JJ, et al. Phase II trial of ixabepilone, an epothilone $\mathrm{B}$ analog, in patients with metastatic breast cancer previously untreated with taxanes. J Clin Oncol. 2007;25:3421-3427.

24. Low JA, Wedam SB, Lee JJ, et al. Phase II clinical trial of ixabepilone (BMS-247550), an epothilone B analog, in metastatic and locally advanced breast cancer. J Clin Oncol. 2005;23: 2726-2734.

25. Perez EA, Lerzo G, Pivot X, et al. Efficacy and safety of ixabepilone (BMS-247550) in a phase II study of patients with advanced breast cancer resistance to an anthracycline, a taxane, and capecitabine. J Clin Oncol. 2007;25:3407-3414.

26. Roché H, Yelle L, Cognetti F, et al. Phase II clinical trial of ixabepilone (BMS-247550), an epothilone B analog, as first-line therapy in patients with metastatic breast cancer previously treated with anthracycline chemotherapy. J Clin Oncol. 2007;25:3415-3420.

27. Thomas E, Tabernero J, Fornier M, et al. Phase II clinical trial of ixabepilone (BMS-247550), an epothilone B analog, in patients with taxane-resistance metastatic breast cancer. J Clin Oncol. 2007;25: 3399-3406.

28. Thomas ES, Gomez HL, Li RK, et al. Ixabepilone plus capecitabine for metastatic breast cancer progressing after anthracycline and taxane treatment. J Clin Oncol. 2007;25:5210-5217.

29. Hortobagyi GN, Perez E, Vrdoljak E, et al. Analysis of overall survival (OS) among patients (pts) with metastatic breast cancer (MBC) receiving either ixabepilone (I) plus capecitabine (C) or C alone: results from two randomized phase III trials [abstract]. Presented at the 2008 ASCO Breast Cancer Symposium; 2008 Sep 5-7; Washington, DC, USA.

30. Horak CE, Lee FY, Xu L, et al. High beta-III tubulin expression in triple-negative (TN) breast cancer (BC) subtype and correlation to ixabepilone response: a retrospective analysis [abstract]. J Clin Oncol. 2009;27(Suppl):15S. 
31. Fisher B, Brown A, Mamounas E, et al. Effect of preoperative chemotherapy on local-regional disease in women with operable breast cancer: findings from National Surgical Adjuvant Breast and Bowel Project B-18. J Clin Oncol. 1997;15:2483-2493.

32. Gradishar WJ. Docetaxel as neoadjuvant chemotherapy in patients with stage III breast cancer. Oncology (Williston Park). 1997;11 (Suppl 8):15-18.

33. Buzdar AU, Singletary SE, Theriault RL, et al. Prospective evaluation of paclitaxel versus combination chemotherapy with fluorouracil, doxorubicin, and cyclophosphamide as neoadjuvant therapy in patients with operable breast cancer. J Clin Oncol. 1999;17:3412-3417.

34. Amat S, Bougnoux P, Penault-Llorca F, et al. Neoadjuvant docetaxel for operable breast cancer induces a high pathological response and breast-conservation rate. Br J Cancer. 2003;88:1339-1345.

35. Estévez LG, Cuevas JM, Antón A, et al. Weekly docetaxel as neoadjuvant chemotherapy for stage II and III breast cancer: efficacy and correlation with biological markers in a phase II, multicenter study. Clin Cancer Res. 2003;9:686-692.

36. Clinicaltrials.gov [homepage on the Internet]. Study to Assess Effectiveness of Giving Combination of Standard Chemotherapy Drugs versus Combination of Standard Chemotherapy and New Drug Ixabepilone When Given Before Surgical Removal of Early Stage Breast Cancer. Available at: http://clinicaltrials.gov/ct2/show/NCT00455533. Accessed March 9, 2010.

37. Clinicaltrials.gov [homepage on the Internet]. Combination Chemotherapy Followed By Docetaxel or Ixabepilone in Treating Patients Who Have Undergone Surgery for Nonmetastatic Breast Cancer. Available from: http://clinicaltrials.gov/ct2/show/NCT00630032. Accessed March 9, 2010.

38. Clinicaltrials.gov [homepage on the Internet]. A Randomized Trial of IXEMPRA versus TAXOL in Adjuvant Therapy of Triple Negative Breast Cancer (TITAN). Available from: http://clinicaltrials.gov/ct2/ show/NCT00789581. Accessed March 9, 2010.

39. Moulder S, Li H, Wang M, et al. A phase II trial of trastuzumab plus weekly ixabepilone and carboplatin in patients with HER2 positive metastatic breast cancer: an Eastern cooperative oncology group trial. Breast Cancer Res Treat. 2010;119:663-671.

40. Rugo HS, Campone M, Amadori D, et al. Randomized phase II study of weekly versus every-3-week ixabepilone plus bevacizumab (ixa/bev) versus paclitaxel plus bev (pac/bev) as first-line therapy for metastatic breast cancer (MBC) [abstract]. J Clin Oncol. 2009;27(Suppl):15S.

41. Jones SE, Erban J, Overmoyer B, et al. Randomized phase III study of docetaxel compared with paclitaxel in metastatic breast cancer. J Clin Oncol. 2005;23:5542-5551.

42. Nabholtz JM, Senn HJ, Bezwoda WR, et al. Prospective randomized trial of docetaxel versus mitomycin plus vinblastine in patients with metastatic breast cancer progressing despite previous anthracycline-containing chemotherapy. 304 Study Group. J Clin Oncol. 1999;17:1413-1424.

43. Bonneterre J, Roché H, Monnier A, et al. Docetaxel vs 5-fluorouracil plus vinorelbine in metastatic breast cancer after anthracycline failure. Br J Cancer. 2002;87:1210-1215.
44. Robert N, Leyland-Jones B, Asmar L, et al. Randomized phase III study of trastuzumab, paclitaxel, and carboplatin compared with trastuzumab and paclitaxel in women with HER-2-overexpressing metastatic breast cancer. J Clin Oncol. 2006;24:2786-2792.

45. Perez EA, Pivot X, Vrdoljak E, et al. A prospective characterization of the resolution of ixabepilone-induced peripheral neuropathy: data from a large registrational program in patients with metastatic breast cancer. Cancer Res. 2009;69:6140.

46. Bunnell C, Vahdat L, Schwartzberg L, et al. Phase I/II study of ixabepilone plus capecitabine in anthracycline-pretreated/resistant and taxane-resistant metastatic breast cancer. Clin Breast Cancer. 2008;8:234-241

47. Thomas ES. Ixabepilone plus capecitabine for metastatic breast cancer progressing after anthracycline and taxane treatment. J Clin Oncol. 2008;26:2223.

48. Jassem J, Thomas E, Gomez H, et al. Phase III study of ixabepilone plus capecitabine in patients with metastatic breast cancer (MBC) progressing after anthracyclines and taxanes: subgroup analysis of patients receiving ixabepilone in the first-line setting [abstract]. Eur J Cancer. 2007;5(Suppl):213.

49. Vahdat L, Fein LE, Karwai MW, et al. Ixabepilone plus capecitabine vs capecitabine in patients with metastatic breast cancer receiving ixabepilone in the first line setting: a pooled analysis from two phase II studies [abstract]. Cancer Res. 2009;69(Suppl):394S

50. Rugo HS, Roché H, Thomas E, et al. Ixabepilone plus capecitabine vs capecitabine in patients with triple negative tumors: a pooled analysis of patients from two large phase III clinical studies [abstract]. Cancer Res. 2009;69(Suppl):225S.

51. Smith JW, Vukelja SJ, Rabe AC, et al. Preliminary toxicity results of a phase II randomized trial of weekly or every-3-week ixabepilone in metastatic breast cancer (MBC) [abstract]. Presented at the 32nd Annual San Antonio Breast Cancer Symposium; 2009 Dec 10-13; San Antonio, TX, USA.

52. Ixempra [package insert]. Princeton, NJ: Bristol-Myers Squibb; 2009.

53. Lee JJ, Swain SM. Peripheral neuropathy induced by microtubule-stabilizing agents. J Clin Oncol. 2006;24:1633-1642.

54. Swain SM, Arezzo JC. Neuropathy associated with microtubule inhibitors: diagnosis, incidence, and management. Clin Adv Hematol Oncol. 2008;6:455-467.

55. Lee JJ, Low JA, Croarkin E, et al. Changes in neurologic function tests may predict neurotoxicity caused by ixabepilone. J Clin Oncol. 2006;24:2084-2091.

56. Orsini LS, Mukhopadhyay P, Peck R, Corey-Lisle P. Quality adjusted time without symptoms or toxicities (Q-TWiST) of ixabepilone plus capecitabine versus capecitabine for metastatic breast cancer (MBC) [abstract]. Presented at the 2009 ASCO Breast Cancer Symposium; 2009 Oct 8-10; San Francisco, CA, USA.
Cancer Management and Research

\section{Publish your work in this journal}

Cancer Management and Research is an international, peer-reviewed open access journal focusing on cancer research and the optimal use of preventative and integrated treatment interventions to achieve improved outcomes, enhanced survival and quality of life for the cancer patient The journal welcomes original research, clinical \& epidemiological

\section{Dovepress}

studies, reviews \& evaluations, guidelines, expert opinion \& commentary, case reports \& extended reports. The manuscript management system is completely online and includes a very quick and fair peerreview system, which is all easy to use. Visit http://www.dovepress.com/ testimonials.php to read real quotes from published authors. 